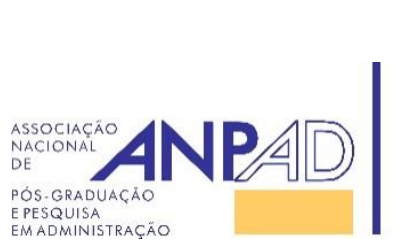

Disponível em

http://www.anpad.org.br/rac

RAC, Rio de Janeiro, v. 21, n. 2, art. 2,

pp. 163-183 Mar./Abr. 2017

http://dx.doi.org/10.1590/1982-7849rac2017150101

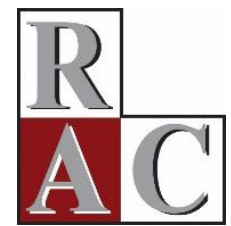

(c) EY

\title{
Novas Fontes, Novas Versões: Contribuições do Acervo da Comissão Nacional da Verdade
} New Sources, New Versions: Contributions Made by the National Truth Commission
Archives

Alessandra Sá Mello Costa ${ }^{1}$ Marcelo Almeida de Carvalho Silva ${ }^{1}$

Pontifícia Universidade Católica do Rio de Janeiro ${ }^{1}$

Artigo recebido em 28.04.2015. Última versão recebida em 09.09.2015. Aprovado em 10.09.2015. Publicado online em 20.07.2016. 


\title{
Resumo
}

$\mathrm{Na}$ área de estudos organizacionais, o interesse dos pesquisadores em utilizar fontes e acervos históricos em suas pesquisas cresce a cada dia (Rowlinson, Hassard, \& Decker, 2014; Yates, 2014). Como forma de enriquecer e aprofundar a discussão sobre esse movimento, a presente pesquisa tem por objetivo refletir sobre possíveis contribuições das fontes reunidas, sistematizadas e produzidas pela Comissão Nacional da Verdade (CNV). Instituída para investigar as graves violações dos direitos humanos cometidas no regime da ditadura civil-militar brasileira, a CNV (a partir de seu acervo) oferece aos pesquisadores das organizações novas versões dos fatos históricos, o que torna possível não só problematizar e rever versões históricas oficiais hegemônicas, mas também investigar fenômenos organizacionais sob outras perspectivas. Assim, após a descrição do processo de constituição e de composição do seu acervo documental, foram elencadas quatro avenidas de pesquisas iniciais: (a) sobre o apoio e a participação da sociedade civil na constituição e manutenção do governo civil-militar brasileiro; (b) sobre a formação de redes de agentes sociais envolvidos no processo de criação e de trabalho da CNV; (c) sobre as relações de trabalho durante o período, como a atuação dos sindicatos ou as práticas de recursos humanos sob um regime autoritário; e (d) sobre o tema da história e memória das empresas.

Palavras-chave: fontes documentais; pesquisa histórica; Comissão Nacional da Verdade; estudos organizacionais.

\begin{abstract}
In the area of organizational studies, researcher interest in using historical sources and archives grows every day (Rowlinson, Hassard, \& Decker, 2014; Yates, 2014). In order to enrich and expand upon the discussion about this movement, the aim of this article is to consider the possible contributions made by sources produced, unified and systemized by the National Truth Commission (CNV in Portuguese). Initially set up to investigate serious human rights violations committed during the Brazilian military dictatorship, the CNV (through its archives) offers organizational researchers new versions of historical facts, thereby allowing them to not only problematize and review official hegemonic historical versions but also to investigate certain organizational phenomena from a range of different perspectives. Thus, after beginning with a description of the process involving the constitution and composition of the CNV's documental archives, the article lists four initial avenues of research (a) the support of civil society in constituting and maintaining the civil-military government in power; (b) the creation of networks of civil agents working on the process of setting up and running the CNV; (c) the labor relations during this period, including union activities and the practices adopted by human resource managers under the authoritarian regime; and finally, (d) the theme of companies' historical backgrounds and memory.
\end{abstract}

Key words: documental sources; historical research; the National Truth Commission; organizational studies. 


\section{Introdução}

$\mathrm{Na}$ área de estudos organizacionais, o interesse dos pesquisadores por fontes e acervos históricos cresce a cada dia (Rowlinson, Hassard, \& Decker, 2014). Uma parte desses estudos assume as fontes históricas como potencial de confirmação e refino de teorias gerais, seleção de variáveis e geração de hipóteses em um contexto teórico específico (Usdiken \& Kipping, 2014). Outra parte prioriza como foco uma melhor compreensão acerca das organizações e empresas nos dias de hoje, a partir da análise de fontes que tornem possível identificar o contexto e o processo histórico de sua constituição (Alcadipani \& Bertero, 2012; Anteby \& Molnar, 2012; Durepos, Mills, \& Mills, 2008). Englobando estudos não somente sobre o passado e o futuro das organizações, mas também acerca do sentido do passado e do futuro para as organizações, alguns pesquisadores interessam-se por identificar e problematizar processos organizacionais por detrás das histórias oficiais das empresas e as razões para que essas histórias sejam escolhidas e não outras (A. M. Costa \& Saraiva, 2011; Decker, 2013). A maior parte das pesquisas, entretanto, interessa-se pela identificação e análise de fontes e acervos históricos que legitimem o resgate e a gestão de uma determinada trajetória histórica, com seus desdobramentos em narrativas memorialísticas, usadas de forma estratégica pelas empresas e organizações (Decker, 2014; Foster, Suddaby, Minkus, \& Wiebe, 2011).

A posição de pesquisa assumida por cada pesquisador que se propõe a trabalhar com história e fontes históricas, de forma articulada com a administração, reflete, porém, diferentes formas de entendimento e de apropriação do próprio fenômeno histórico. E dada a sua importância, as discussões e debates acerca do processo de identificação, coleta e uso das fontes históricas (método histórico) vêm ganhando um espaço cada vez maior em periódicos e fóruns especializados, seja com o foco mais específico nas fontes e dados históricos (Kipping, Wadhwani, \& Bucheli, 2014; Lipartito, 2014), seja no que se refere aos procedimentos metodológicos propriamente ditos (Yates, 2014). Nesse contexto, (a) assumindo que o resgate dos aspectos históricos permite uma maior compreensão das clivagens de poder e uma maior aproximação dos pesquisadores com suas realidades locais; e (b) buscando uma adesão cada vez maior às propostas de aprofundamento e maior envolvimento de pesquisadores organizacionais com a perspectiva histórica para além de um engajamento superficial com o passado, este artigo tem por objetivo refletir sobre possíveis contribuições para a área de estudos organizacionais das fontes históricas reunidas, sistematizadas e produzidas no Brasil pela Comissão Nacional da Verdade $(\mathrm{CNV})$.

O Brasil foi o último país latino-americano a instaurar uma comissão da verdade e o governo brasileiro precisou de quase 50 anos para iniciar efetivamente esse mecanismo de justiça de transição (dito suprapartidário) de rever e problematizar a sua história e as suas memórias no que diz respeito às violações dos direitos humanos no período da sua ditadura civil-militar. Distinto, por ter um caráter tardio (Dias, 2013), esse movimento, no Brasil, buscou esclarecer os casos de morte, de torturas, de desaparecimentos forçados e de ocultação de cadáveres, identificando e tornando públicos os locais, as estruturas, as instituições, as empresas e as circunstâncias relacionadas a essas práticas.

Como desdobramento, foram não só levantadas diversas novas informações como também revisitadas versões anteriores a partir de pesquisa documental e de tomada de depoimentos, todas disponibilizadas em acervos abertos para a consulta pública. A relevância da criação de acervos disponíveis para a consulta pública no Brasil merece atenção, uma vez que são vários os instrumentos jurídicos que cerceiam a liberdade de conhecer e consultar documentos oficiais. E, particularmente, em relação ao objeto em análise, segundo Schmidt (2007), a demanda da sociedade civil pela abertura dos arquivos da repressão da ditadura civil-militar brasileira (que o autor chama de "batalhas pela memória", p. 135) vem ocorrendo desde o final dos anos 1970 e "não se encerrou por decreto com a anistia e nem mesmo com o final da ditadura e a restauração das liberdades democráticas" (p. 135). 


\section{A Comissão Nacional da Verdade (CNV)}

\section{Justiça de transição e as comissões da verdade}

Segundo Bloch (2001), a história não é entendida como uma ciência do passado, mas, ao contrário, é a ciência dos homens no tempo, cuja relevância reside no valor atribuído ao presente para a compreensão do passado. A partir dessa perspectiva, ocorre um profundo questionamento tanto da noção de fato histórico (não mais considerado um objeto dado e acabado, uma vez que é resultado da construção do historiador) quanto da noção de documento (noção ampliada em que não é mais considerado algo objetivo e inocente). A própria ausência de documentos passa a ser significativa, pois elucida que estes são sempre produtos de uma sociedade que os fabricou segundo relações de forças e de poder. Ao mesmo tempo, o passado passa a ser revisitado, questionado e desafiado, sempre em consonância com inquietações (e demandas) do presente.

Nesse sentido, os maiores desafios para os pesquisadores contemporâneos são os relacionados às fontes que utilizam, as quais, ao serem descobertas, produzidas, revisitadas, articuladas e então disseminadas, tornam possível a recorrente (re)escrita da história e dos fatos históricos. Esse movimento, complexo em essência e fundamental para a problematização do conhecimento, adquire grande visibilidade quando nos deparamos com os processos de instauração das comissões da verdade mecanismos criados para apurar e reparar crimes de violação dos direitos humanos, que tornam possível problematizar e rever versões históricas oficiais hegemônicas.

As comissões da verdade surgem no final dos anos 1980, no âmbito do direito internacional de justiça transicional, pela convergência entre demandas por justiça e por transição democrática. $\mathrm{O}$ processo de justiça transicional compõe-se de pelo menos quatro dimensões fundamentais: "a reparação; o fornecimento da verdade e a construção da memória; a regularização da justiça e o restabelecimento da igualdade perante a lei; e a reforma das instituições perpetradoras de violações contra os direitos humanos" (Abrão, 2011, p. 119). No caso do processo de justiça de transição no Brasil, pode-se dizer que a sua principal característica é a de que "as medidas de reparação têm sido o eixo estruturante da agenda que procura tratar do legado de violência da ditadura militar de 1964-1985" (Abrão, 2011, p. 119).

Como destaca Pinto (2010, p. 129), o termo

foi cunhado para expressar métodos e formas de responder a sistemáticas e amplas violações aos direitos humanos [...] [e] não expressa nenhuma forma especial de justiça, mas diversas iniciativas que têm por intuito reconhecer o direito das vítimas, promover a paz, facilitar a reconciliação e garantir o fortalecimento da democracia.

Ainda de acordo com esse autor, a área ganhou maior relevância a partir da definição da Corte Interamericana de Direitos Humanos de que "todos os Estados estão sujeitos a quatro obrigações: a) tomar medidas para prevenir violações aos direitos humanos; b) conduzir investigações quando as violações ocorrerem; c) impor sanções aos responsáveis pelas violações e d) garantir reparação para as vítimas" (Pinto, 2010, p. 129).

Todavia, cabe destacar que a justiça transicional pode adquirir diversas configurações, sendo a instauração de comissões da verdade apenas uma delas. Outros exemplos seriam: julgamentos criminais, reforma das instituições políticas, formas de compensação das vítimas, construção de memoriais, entre outros. Criadas em momentos de transição de governos autoritários para governos democráticos, a fim de legitimar a ruptura com o passado e promover alguma forma de reconciliação nacional, as diferentes comissões da verdade - sempre temporárias - buscam, por meio de testemunhos e documentos, compreender o passado (o período autoritário e de repressão) em um contexto mais amplo, estabelecendo um cenário mais completo acerca das causas, da natureza e da extensão das violações aos direitos humanos que foram cometidas durante o período (Pinto, 2010). 


\section{A Comissão da Verdade no Brasil}

No dia 18 de novembro de 2011, o governo federal, por meio da Lei no 12.528 , criou a CNV. Até esse momento, o eixo central das ações do governo brasileiro (em relação à sua experiência autoritária) baseava-se apenas em ações de reparações às vítimas da ditadura civil-militar e seus familiares sem considerar efetivamente nem o questionamento das versões históricas acerca da repressão no período, nem a justiça em relação aos agentes da violência do Estado. A história desse colegiado, contudo, não se iniciou nessa data.

Segundo Santos (2010), desde 2007 a Secretaria de Direitos Humanos e o Ministério da Justiça demonstravam-se favoráveis à "investigação do passado como uma forma de aprofundamento da democracia, defendendo a não aplicação da Lei de Anistia ... aos crimes de tortura, assassinato e desaparecimento forçado, praticados pelos agentes do Estado contra os dissidentes políticos durante a ditadura" (p. 127). Contudo, apenas em dezembro de 2008 essa investigação começou a ganhar materialidade quando a $11^{\text {a }}$ Conferência Nacional dos Direitos Humanos (CNDH) aprovou como uma das propostas do seu sétimo eixo (Direito à Memória e Verdade) a criação da Comissão Nacional de Verdade e Justiça.

Podemos considerar que essa foi uma das primeiras menções oficiais à criação de uma comissão com plenos poderes de investigação dos crimes ocorridos durante a ditadura civil-militar brasileira. Para a realização do seu trabalho, o texto da CNDH requisitava que tal comissão pudesse convocar qualquer pessoa como testemunha ou acusado (sob pena de desobediência, caso não comparecesse), requisitar cópia de qualquer documento que pudesse considerar útil para sua investigação e, por fim, que lhe fosse concedido o acesso irrestrito a qualquer órgão público com o objetivo de viabilizar o acesso tanto a documentos e informações quanto a possíveis testemunhas e acusados. Além disso, as propostas relacionadas ao eixo Direito à Memória e Verdade previam o fomento a estudos e pesquisa sobre a atuação dos diversos segmentos sociais e instituições na ditadura brasileira, entre elas, pode-se destacar, o empresariado nacional (Secretaria de Direitos Humanos, 2008).

Apesar da resistência do Ministério da Defesa e da Advocacia Geral da União (AGU), que acreditavam que a retomada das discussões acerca do passado pudesse desestabilizar o país politicamente (Santos, 2010), o presidente Luiz Inácio Lula da Silva lançou, em 22 de dezembro de 2009, o terceiro Programa Nacional de Direitos Humanos (PNDH-3). Fixado pelo Decreto n 7.037 e publicado no Diário Oficial da União no dia 22 de dezembro de 2009 (Decreto nº 7.037, 2009), o texto do PNDH-3 tomou por base os eixos e propostas da $11^{\mathrm{a}} \mathrm{CNDH}$.

Dessa forma, o direito à memória e à verdade, previsto na $\mathrm{CNDH}$, ganhou oficialidade por meio do eixo orientador 6, que trazia em seu interior três diretrizes básicas, entre as quais o Reconhecimento da memória e da verdade como Direito Humano da cidadania e dever do Estado (diretriz 23), cujo principal objetivo era

promover a apuração e o esclarecimento público das violações de Direitos Humanos praticadas no contexto da repressão política ocorrida no Brasil no período fixado pelo art. $8^{\circ}$ do ADCT da Constituição [de 1946 até 1988], a fim de efetivar o direito à memória e à verdade histórica e promover a reconciliação nacional (Decreto $\left.n^{\circ} 7.037,2009\right)$.

Ainda, no mesmo decreto, a referida diretriz estabelecia como primeira ação programática a designação de um grupo de trabalho para elaborar o projeto de lei que instituiria a CNV.

De acordo com Paiva e Pomar (2011), o Projeto de Lei ${ }^{\circ}$ 7.376, aprovado apenas em 2011, criou uma estrutura "muito distante daquela idealizada pelos ativistas de direitos humanos" (p. 113). Um manifesto assinado por familiares de mortos, ex-presos, desaparecidos políticos e entidades de direitos humanos reivindicava a mudança do PL 7.376 para que a CNV apurasse os crimes da ditadura militar com autonomia e sem sigilo, pois a manutenção do texto, como encaminhado ao Congresso, faria da CNV "mais uma farsa, um engodo" (Grupo Tortura Nunca Mais/RJ, 2011, p. 1). As principais contestações desses grupos expressas no manifesto dizem respeito (a) à abrangência do período a ser 
investigado (de 1946 até 1988) e na consequente falta de foco no período da ditadura civil-militar (de 1964 até 1985); (b) à falta de autonomia política e orçamentária (o texto aprovado vinculava a CNV à Casa Civil); (c) à possibilidade de membros das forças armadas e órgãos de segurança do estado integrarem a Comissão; e (d) à falta de poder punitivo, já que a lei não previa caráter jurisdicional ou persecutório à CNV (Paiva \& Pomar, 2011).

Cabe ressaltar que 2010 foi um ano de eleições presidenciais no Brasil e, por isso, os desdobramentos do PNDH-3 e a discussão dos moldes em que seria criada a CNV foram, de acordo com pesquisadores, envoltos em debates eleitorais, políticos e ideológicos (Dias, 2013). A oposição ao governo desqualificava as motivações do plano e seu conteúdo e havia divergências dentro do próprio governo com proeminência para a insatisfação do Ministério da Defesa que, conforme dito anteriormente, enxergava, no conteúdo do PNDH-3, uma possível fonte de instabilidade jurídica e política. Os pontos de discordância se referiam ao entendimento de que a Lei da Anistia seria revogada e à falta de referência às esquerdas armadas (Dias, 2013).

Acrescentando mais um ingrediente ao já conturbado cenário, em 2010, posteriormente ao lançamento do PNDH-3 (mas ainda antes do projeto de lei de criação da CNV), o Brasil foi condenado na Corte Interamericana de Direitos Humanos (CIDH) da Organização dos Estados Americanos (OEA) como resultado da ação movida por familiares de mortos e desaparecidos na Guerrilha do Araguaia ação armada desencadeada pelo PCdoB entre 1972 e 1974 na região de Marabá no Pará (Adam, Silva, \& Leonetti, 2013; CNV, 2014a). Em seu documento final, a CIDH se manifestou no sentido de valorizar a criação de uma comissão, mas ressaltou que os trabalhos de tal comissão "não substituem a obrigação do Estado de estabelecer a verdade e assegurar a determinação judicial de responsabilidades individuais, através dos processos judiciais penais" (CIDH, 2010, p. 107). Apesar de o Brasil não ter sido condenado diretamente a instaurar uma comissão da verdade, haja vista a própria intenção de criação da CNV anterior à condenação, seria imprudente desconsiderar a influência que o ato da CIDH teve na criação da CNV ocorrida no ano seguinte (Paiva \& Pomar, 2011).

Foi nesse contexto de disputas políticas e ideológicas que a presidente Dilma Rousseff sancionou a lei que criou a CNV em 18 de novembro de 2011, sem considerar as contestações dos grupos ligados aos direitos humanos, vítimas e familiares das vítimas. Seis meses depois de sancionada, em 16 de maio de 2012, os membros da comissão foram nomeados, podendo, então, dar início aos trabalhos de pesquisa. O prazo estabelecido para a realização dos trabalhos era de dois anos, devendo, ao término desse período, ser produzido um relatório com as atividades realizadas, os fatos examinados, as conclusões e as recomendações. Contudo, sob a alegação do surgimento de novas fontes de informações e novas frentes de trabalho, o prazo para conclusão dos trabalhos foi estendido até 16 de dezembro de 2014.

\section{A estrutura da Comissão Nacional da Verdade}

A comissão estruturou-se em colegiado, subcomissões e grupos de trabalho, ligados à Casa Civil da Presidência da República, não tendo, como mencionado anteriormente, caráter jurisdicional ou persecutório. O colegiado foi formado por sete cargos remunerados, ocupados por brasileiros "de reconhecida idoneidade e conduta ética, identificados com a defesa da democracia e da institucionalidade constitucional, bem como com o respeito aos direitos humanos" (Lei $\left.\mathrm{n}^{\circ} 12.528,2011\right)$. Assim, foram nomeados para compor a CNV (a) o ex-Procurador Geral da República, Claudio Fonteles; (b) o ministro do Superior Tribunal de Justiça, Gilson Dipp; (c) o advogado e ex-Ministro da Justiça que, durante a ditadura, atuou diretamente na justiça militar na defesa de presos políticos, José Carlos Dias; (d) o advogado e ex-secretário-geral do Ministério da Justiça e consultor da Unesco, José Paulo Cavalcanti; (e) a psicanalista Maria Rita Kehl; (f) o cientista político, ex-secretário de direitos humanos, ex-integrante do grupo de trabalho que preparou o projeto de lei que deu origem à CNV e membro da ONU, Paulo Sérgio Pinheiro; e (g) a advogada, ex-integrante do Conselho Nacional de Política Criminal e Penitenciária e ex-secretária adjunta de Justiça do Estado do Rio de Janeiro, Rosa Maria Cardoso. Deve-se chamar a atenção para o fato de que a comissão era composta, em sua maioria, por advogados e juristas, não alcançando, assim, a composição pluralista prevista na lei que a instituiu. 
Dos sete membros da formação original, apenas cinco permaneceram em atividade até a conclusão dos trabalhos. Em outubro de 2012, Gilson Dipp se afastou por problemas de saúde e Claudio Fonteles renunciou ao seu cargo, deixando a comissão em junho de 2013. Dos dois, somente Fonteles foi substituído. Pedro Dallari - advogado e membro do Conselho Diretor do Centro de Estudos de Justiça das Américas (CEJA), ligado à OEA - substituiu Fonteles em setembro do referido ano, fato que levou o relatório final a ser assinado por apenas seis membros. Aos membros do colegiado agregavam-se assessores, servidores públicos, auxiliares técnicos e administrativos, estagiários, consultores, colaboradores e voluntários, totalizando mais de 217 pessoas vinculadas à $\mathrm{CNV}$, mesmo que em momentos distintos (CNV, 2014b).

De acordo com o seu sítio eletrônico, o plano de trabalho da comissão dividiu-se em três subcomissões, sendo a principal delas a subcomissão de Pesquisa, Geração e Sistematização das Informações, em que se encontravam alocados os treze Grupos de Trabalho (GT) temáticos que constituíram a atividade fim da CNV, sendo cada um desses grupos coordenado por, no mínimo, um membro da comissão e contando com assessores, consultores ou pesquisadores (CNV, 2015a).

No decorrer dos trabalhos da comissão, os diferentes GTs foram sendo modificados, sendo os principais: GT Ditadura e Gênero (responsável: Paulo Sérgio Pinheiro); GT Araguaia (responsáveis: José Carlos Dias, Rosa Cardoso e Maria Rita Kehl); GT Contextualização, Fundamentos e Razões do Golpe Civil-Militar de 1964 (responsável: Rosa Cardoso); GT Estrutura de Repressão (responsável: José Paulo Cavalcanti); GT Mortos e Desaparecidos Políticos (responsáveis: José Carlos Dias e Rosa Cardoso); GT Graves Violações de Direitos Humanos no Campo ou Contra Indígenas (responsável: Maria Rita Kehl); GT Operação Condor (responsável: Rosa Cardoso); GT Estado Ditatorial-Militar (responsável: Claudio Fonteles); GT Papel das Igrejas durante a Ditadura (responsável: Paulo Sérgio Pinheiro); GT Perseguição a Militares (responsável: Rosa Cardoso); e o último GT criado, Ditadura e Repressão aos Trabalhadores e ao Movimento Sindical (responsável: Rosa Cardoso).

À principal subcomissão, juntaram-se ainda a Subcomissão de Relações com a Sociedade Civil e Instituições (coordenada por Paulo Sérgio Pinheiro e Rosa Cardoso) e responsável pela realização de audiências e eventos públicos; e a Subcomissão de Comunicação Externa (coordenada por Rosa Cardoso), responsável pela assessoria de comunicação (site da CNV, relação com a imprensa e redes sociais) e ouvidoria (atendimento de demandas dirigidas à comissão). A estrutura da CNV continha ainda três áreas de suporte: a secretaria-executiva, responsável pela gestão e administração; a gestão da informação, responsável pelo planejamento, estrutura e gerenciamento dos sistemas de informação e recursos; e o núcleo da comissão dentro do Arquivo Nacional.

Cabe destacar que a comissão buscou estabelecer uma ativa rede de apoio à pesquisa, composta por diversas comissões da verdade (ao todo foram 29 comissões da verdade com acordo estabelecido de cooperação técnica). Essa rede, formada por universidades e outras instituições, tornou possível reverberar as possibilidades de investigação ampliando a abrangência das pesquisas e viabilizando o acesso a mais documentos e testemunhos (Instituto de Estudos da Religião, 2012). Como desdobramento, além do apoio técnico e informacional, tais parcerias possibilitaram, ao mesmo tempo, a representação ramificada da comissão por todo o território nacional, permitindo (a) a realização de audiências, atos públicos e atividades de pesquisa e depoimentos por todo o país; e (b) o financiamento de pesquisas relacionadas ao tema.

Esse foi o caso de instituições, como a Fundação Carlos Chagas Filho de Amparo à Pesquisa do Estado do Rio de Janeiro (FAPERJ) - que lançou o programa Apoio ao estudo de temas relacionados ao direito à memória, à verdade e à justiça relativas a violações de direitos humanos - e da Coordenação de Aperfeiçoamento de Pessoal de Nível Superior (Capes), que desenvolveu um edital em conjunto com a Secretaria de Direitos Humanos para a concessão de bolsas de mestrado e doutorado para pesquisas voltadas ao tema da ditadura civil-militar (CNV, 2012). Entretanto, no que diz respeito mais especificamente à esfera de atuação dos pesquisadores da área da Administração, é importante mencionar a falta de envolvimento destes e de suas instituições representativas com a CNV. Assim, não foram identificadas menções a solicitações, colaborações ou projetos em parceria com escolas de 
negócios, com a Associação Nacional de Pós-Graduação e Pesquisa em Administração (ANPAD) e com entidades ligadas ao comércio e à indústria, como a FIRJAN e a FIESP.

\section{O Acervo da Comissão Nacional da Verdade}

Na fase inicial dos trabalhos, a comissão ocupou-se de sua estruturação administrativa, da organização da pesquisa, bem como do contato com os familiares das vítimas. Em julho de 2012, dois meses após sua criação, promoveu um encontro com diversas instituições da sociedade civil com o objetivo de receber sugestões, informações e documentos. Ainda em sua fase inicial, definiu quais seriam os temas investigados, as fontes e os meios de acesso a elas. Com base nesses temas, a comissão dividiu-se em grupos de trabalho e, a partir de dezembro de 2012, deu início às pesquisas. Em 21 de maio de 2013, pouco após completar um ano de vida, a CNV publicou um primeiro balanço de suas atividades no qual explicitou as suas formas de atuação (pesquisa, articulação com a sociedade e comunicação) e os resultados até então alcançados (até a publicação do balanço já havia mais de 260 testemunhos, atingindo o total de 565 ao término dos trabalhos).

Pode-se destacar que a comissão procurou, durante sua trajetória, firmar um diálogo com a sociedade civil e demais instituições aderentes aos temas propostos para investigação. No total, foram realizadas 80 audiências públicas (ocorridas entre julho de 2012 e outubro de 2014), dentre as quais três foram consideradas reuniões ampliadas cujo escopo era conhecer as expectativas (a) dos Grupos de Verdade, Memória e Justiça; (b) das Comissões Estaduais, Municipais; (c) das entidades profissionais; (d) das organizações da sociedade civil; e (e) das universidades. Ao mesmo tempo, para além dessas audiências, a CNV estabelecia contato com a sociedade civil por meio de sua ouvidoria, aberta a qualquer cidadão com acesso à internet, e das redes sociais administradas pela Coordenação Geral de Comunicação e Imprensa.

Ainda no que diz respeito ao processo de diálogo estabelecido com a sociedade, é possível afirmar que a mídia foi um canal importante, transformando as atividades em pauta da CNV em reportagens de rádio, televisão, jornais, revistas e sites de notícias (principalmente nos casos mais famosos, como a exumação do corpo do ex-presidente deposto João Goulart; o desaparecimento do deputado Rubens Paiva e do estudante Stuart Angel; e a morte do jornalista Vladimir Herzog). Ou seja, a expressiva cobertura pelos veículos de comunicação também possibilitou que a sociedade brasileira acompanhasse o funcionamento da comissão.

Foi por meio das reportagens e artigos publicados na imprensa que se tornou possível, por exemplo, saber que, durante seu período de trabalho, a CNV esteve às voltas com disputas e tramas internas suscitadas, muitas vezes, por divergências de posicionamento em relação a pontos críticos do trabalho da comissão (Arruda, 2013; Bocchini \& Bonis, 2013; Duailibi, 2014). A discussão dos trabalhos ainda em andamento, a exposição de alguns membros na grande mídia, além dos diferentes níveis de dedicação dos membros aos trabalhos da comissão, são alguns dos pontos entendidos como desarmônicos entre os integrantes da comissão. Ademais, alguns membros do colegiado defendiam que, no relatório final, constasse a sugestão de revisão da Lei da Anistia, questão não admitida por outros participantes da comissão. Por último, o próprio sistema de coordenação por rodízio, em lugar de estimular acordos e pactos, contribuiu para acirrar disputas, contradições e conflitos (Duailibi, 2014).

Apesar disso, após dois anos e sete meses de trabalhos, disputas e controvérsias, a CNV entregou seu relatório final à presidente Dilma Rousseff, no dia 10 de dezembro de 2014 (Dia Internacional dos Direitos Humanos), em uma cerimônia em Brasília. Como esperado, o conteúdo do relatório foi contestado e envolto em polêmicas, assim como a própria $\mathrm{CNV}$ ao longo de sua história. A entrega do relatório (classificado como revanchista pelos militares e como insatisfatório pelos defensores dos direitos humanos) colocou um ponto final nos trabalhos da comissão que pôde, assim, encerrar suas atividades no dia 16 de dezembro de 2014, data-limite para a conclusão dos trabalhos e dissolução da 
comissão (apenas uma pequena estrutura encarregada da organização e disponibilização dos documentos no Arquivo Nacional foi mantida).

Durante todo o seu trabalho, a comissão produziu e disponibilizou documentos de naturezas diversas e com diferentes matizes. Entretanto, cabe aqui a ressalva de que a CNV já partiu de um vasto material produzido por outras entidades, como: a Comissão Especial sobre Mortos e Desaparecidos Políticos (CEMDP) da Secretaria de Direitos Humanos do Governo Federal; o grupo Brasil: Nunca Mais; a Comissão de Anistia; a Comissão de Familiares de Mortos e Desaparecidos Políticos; o grupo Tortura Nunca Mais do Rio de Janeiro; o Centro pela Justiça e o Direito Internacional (CEJIL); e as Comissões Estaduais da Verdade. Durante quase cinquenta anos, essas instituições produziram diversos documentos e livros (ver os livros Brasil: nunca mais; Direito à memória e à verdade: Comissão Especial sobre Mortos e Desaparecidos Políticos; Dossiê de mortos e desaparecidos políticos a partir de 1964; e o projeto Memorial Pessoas Imprescindíveis) sobre os quais a CNV, assumidamente, construiu sua pesquisa e acrescentou sua contribuição por meio de seus documentos aqui mapeados.

Um bom começo no mapeamento dessa produção pode ser o próprio Portal da Comissão. Pesquisando entre outubro de 2014 e janeiro de 2015, foram mapeados 34 relatórios parciais de pesquisa, 45 publicações contendo discursos, apresentações públicas, textos individuais dos membros e notas públicas divulgadas pela CNV e, ainda, 422 notícias publicadas no sítio eletrônico da CNV que fazem referências aos trabalhos da comissão. Além disso, as próprias páginas virtuais do sítio eletrônico foram mapeadas e cadastradas como fonte de informações. Destas, foram catalogadas 18 páginas com informações institucionais da CNV (dados sobre constituição, membros, equipe e resoluções) e mais 3 páginas dedicadas a descrever os grupos de trabalho. Por fim, foram catalogadas as páginas de audiências contendo aproximadamente 95 eventos, dentre os quais 59 audiências públicas das cerca de 75 realizadas, além de tomadas de depoimentos, apresentações púbicas de relatórios, diligências, atos sindicais, entre outros (CNV, 2013). Alguns desses eventos possuem, inclusive, links para seus respectivos vídeos na página da CNV no portal YouTube (2014).

Segundo o relatório final da comissão, foram publicados 470 vídeos na página (YouTube, 2014), acessados quase 300.000 vezes. Em fevereiro de 2015, após a realização desse levantamento, dando continuidade ao processo de finalização dos trabalhos, o portal da CNV sofreu modificações para que fossem disponibilizados, basicamente, os laudos periciais que serviram de base para a confecção do relatório final. Ao todo, foram publicados 40 laudos periciais até 13/02/2015 (CNV, 2015b).

Afora a riqueza de todo esse material a ser ainda explorado, cabe destacar o relatório final da Comissão como fonte de pesquisa. Esse documento contém cerca de 4.300 páginas divididas em três volumes e está inteiramente disponível para acesso no sítio eletrônico da $\mathrm{CNV}$ (http://www.cnv.gov.br/textos-do-colegiado/586-epub.html).

O primeiro volume do relatório divide-se em cinco partes e dezoito capítulos conforme a Tabela 1.

Tabela 1

\section{Detalhamento do Volume Um do Relatório Final da CNV}

\begin{tabular}{lcl}
\hline Parte & $\mathbf{N}^{\mathbf{o}}$ & Título do capítulo/Texto \\
\hline Parte I & 1 & A criação da Comissão Nacional da Verdade \\
Parte I & 2 & As atividades da CNV \\
Parte II & 3 & Contexto histórico das graves violações entre 1946 e 1988 \\
Parte II & 4 & Órgãos e procedimentos da repressão política \\
Parte II & 5 & A participação do Estado brasileiro em graves violações no exterior \\
Parte II & 6 & Conexões internacionais: a aliança repressiva no Cone Sul e a Operação Condor \\
\hline
\end{tabular}


Tabela 1 (continuação)

\begin{tabular}{lcl}
\hline Parte & $\mathbf{N}^{\mathbf{o}}$ & Título do capítulo/Texto \\
\hline Parte III & 7 & Quadro conceitual das graves violações \\
Parte III & 8 & Detenções ilegais e arbitrárias \\
Parte III & 9 & Tortura \\
Parte III & 10 & Violência sexual, violência de gênero e violência contra crianças e adolescentes \\
Parte III & 11 & Execuções e mortes decorrentes de tortura \\
Parte III & 12 & Desaparecimentos forçados \\
Parte IV & 13 & Casos emblemáticos \\
Parte IV & 14 & A Guerrilha do Araguaia \\
Parte IV & 15 & Instituições e locais associados a graves violações de direitos humanos \\
Parte IV & 16 & A autoria das graves violações de direitos humanos \\
Parte IV & 17 & O Judiciário na ditadura \\
Parte V & 18 & Conclusões e recomendações \\
\hline
\end{tabular}

Nota. Fonte: A tabela foi elaborada pelos autores com base no relatório final da Comissão Nacional da Verdade. (2014b). Relatório da Comissão Nacional da Verdade (Vol. 1). Brasília, DF. Recuperado de http://www.cnv.gov.br/images/pdf/relatorio/volume_1_digital.pdf

Por meio desse volume, buscou-se atingir o objetivo de examinar e esclarecer as graves violações dos direitos humanos e, para isso, descreveu-se minuciosamente o período do regime militar, suas estruturas de repressão, as instituições envolvidas, os métodos de tortura, os casos emblemáticos e a responsabilidade dos autores de tais violações. As suas 976 páginas começam discorrendo sobre a CNV, sendo o primeiro capítulo dedicado a explicar a sua criação; seus antecedentes históricos; as demais comissões da verdade internacionais; e o mandado legal da comissão. Por sua vez, o capítulo dois dedica-se a detalhar as atividades da comissão; sua organização interna; e o seu relacionamento com as demais organizações públicas, Forças Armadas e sociedade civil.

A partir da segunda parte, esse volume procura descrever detalhadamente as violações dos direitos humanos cometidas pelo regime militar. Para tal, contextualiza o cenário político brasileiro desde a democracia do período constitucional de 1946 até o processo de redemocratização de 1988. Contudo, é no período do governo militar, de 1964 até 1985, que o relatório se detém com maior atenção e, em relação a esse período, procura narrar de forma pormenorizada os órgãos e procedimentos de repressão, bem como os métodos e práticas utilizados pelo Estado brasileiro nas violações dos direitos humanos.

Assim, após descrever a criação dos órgãos de repressão política, a participação e a aliança do Brasil nas violações dos direitos humanos no exterior (capítulos quatro, cinco e seis, respectivamente), o volume I do relatório dedica todos os seis capítulos da terceira parte (404 páginas) a analisar os diferentes tipos de violações consideradas graves: a prisão ou detenção ilegal ou arbitrária; tortura; execução sumária, arbitrária ou extrajudicial e outras mortes imputadas ao Estado; e o desaparecimento forçado e ocultação de cadáver. A cada uma dessas violações, é dedicado um capítulo específico, acrescentando-se ainda um capítulo sobre a violência sexual de gênero e a violência contra crianças e adolescentes.

O capítulo que abre a quarta parte do volume traz os denominados casos emblemáticos, como forma de ilustrar e exemplificar os relatos de violação dos direitos humanos relatados na parte três. Entre esses casos estão a repressão contra militares, trabalhadores, sindicalistas, camponeses e grupos de políticos insurgentes. Ao final desse capítulo, são descritos os casos de violência e terrorismo do Estado contra a sociedade civil, mais especificamente os casos da estilista Zuzu Angel (morta em acidente automobilístico que, segundo o relatório, foi causado intencionalmente visando à sua morte) e do atentado do Riocentro (tentativa frustrada de atentado à bomba no show em comemoração ao Dia do 
Trabalho, quando um militar morreu e outro ficou gravemente ferido devido à explosão antecipada do artefato que pretendiam colocar no local).

O capítulo seguinte (capítulo 14) trata de um dos casos de resistência mais famosos do período ditatorial, que são os trágicos acontecimentos conhecidos como Guerrilha do Araguaia, ocorridos no Pará, quando integrantes do PCdoB se estabeleceram na região perto do rio Araguaia, em 1967, com o intuito de iniciar uma revolução socialista. Os guerrilheiros foram duramente combatidos a partir de 1972 e, em 1974, a guerrilha foi exterminada com a morte dos revoltosos. Em 1975, o governo iniciou a chamada Operação Limpeza, um processo metódico de ocultação de cadáveres e dos demais fatos ocorridos na região. Essa guerrilha ganha proeminência, não apenas pela violência com que foram combatidos os guerrilheiros e camponeses e pela política de sigilo do governo, mas principalmente porque ela foi a causa da condenação do governo brasileiro na corte Interamericana de Direitos Humanos.

Novamente, como forma de atingir os objetivos previamente definidos na lei que a criou, a CNV expõe, no capítulo 15, as instituições e locais onde as violações dos direitos humanos ocorreram. Dessa forma, são citadas as unidades militares e policiais, bem como os locais clandestinos utilizados para detenção, execução e tortura de presos políticos. Apesar de não terem sido apresentados todos os locais utilizados pelas estruturas repressivas, foram listados 230 deles entre batalhões da polícia e do exército, hospitais militares, presídios, delegacias, aeroportos e bases aéreas, assim como casas clandestinas espalhadas por todo o território nacional, sendo alguns locais descritos com fotos e plantas das instalações na época.

Encaminhando-se para o final do primeiro volume, o relatório traz, em seu décimo-sexto capítulo, a lista das 377 pessoas responsabilizadas pelas graves violações dos direitos humanos. De acordo com a CNV, a participação dos agentes públicos nesses atos ocorreu de forma distinta e, por isso, optaram por estabelecer diferentes níveis de responsabilidade. O penúltimo capítulo traz a atuação do judiciário durante o período da ditadura desde a justiça comum, passando pela justiça militar, até o Superior Tribunal Federal. O capítulo final desse volume - o único da parte cinco - contém as conclusões, com destaque para a confirmação das graves violações dos direitos humanos cometidas, bem como de crimes contra a humanidade. Traz, ainda, recomendações, como: o reconhecimento, por parte das Forças Armadas, de sua responsabilidade nas graves violações cometidas; a determinação da responsabilidade jurídica dos agentes públicos que causaram essas graves violações; a revogação da Lei de Segurança Nacional de 1983; o prosseguimento dos trabalhos da CNV com foco na localização, identificação e entrega dos restos mortais de desaparecidos políticos; e a preservação da memória das graves violações dos direitos humanos.

O segundo volume do relatório final reúne nove textos denominados textos temáticos e trata de casos e violações a grupos específicos, como os próprios militares perseguidos, camponeses, igrejas cristãs, universitários, homossexuais, índios, bem como da resistência da sociedade civil às graves violações dos direitos humanos, conforme a Tabela 2. 
Tabela 2

Detalhamento do Volume 2 do Relatório Final da CNV

\begin{tabular}{lll}
\hline Volume & Texto & Título \\
\hline Vol. 2 & Texto 1 & Violações de direitos humanos no meio militar \\
Vol. 2 & Texto 2 & Violações de direitos humanos dos trabalhadores \\
Vol. 2 & Texto 3 & Violações de direitos humanos dos camponeses \\
Vol. 2 & Texto 4 & Violações de direitos humanos nas igrejas cristãs \\
Vol. 2 & Texto 5 & Violações de direitos humanos dos povos indígenas \\
Vol. 2 & Texto 6 & Violações de direitos humanos na universidade \\
Vol. 2 & Texto 7 & Ditadura e homossexualidades \\
Vol. 2 & Texto 8 & Civis que colaboraram com a ditadura \\
Vol. 2 & Texto 9 & A resistência da sociedade civil às graves violações de direitos humanos \\
\hline
\end{tabular}

Nota. Fonte: A tabela foi elaborada pelos autores com base no relatório final da Comissão Nacional da Verdade. (2014a). Relatório da Comissão Nacional da Verdade. Textos temáticos (Vol. 2). Brasília, DF. Recuperado de http://www.cnv.gov.br/images/pdf/relatorio/volume_1_digital.pdf

Esse volume inicia-se com a apresentação dos casos de perseguição, prisão e tortura dos militares opositores ao regime. Segundo o relatório, aproximadamente 6.500 militares entre praças e oficiais das três forças - Exército, Marinha e Aeronáutica - e das polícias estaduais foram perseguidos pelo regime ditatorial. É importante o destaque dado a esse grupo, uma vez que o golpe, executado por militares, vitimou também integrantes das Forças Armadas, que foram presos e torturados.

O segundo texto temático - Violações de direitos humanos dos trabalhadores - expõe a perseguição a trabalhadores e líderes sindicais durante o regime militar. Esse texto descreve a articulação entre as elites civis (urbanas e agrárias) e as elites militares na conspiração, financiamento e execução do golpe. Segundo o relatório, essas elites consideravam - cada uma por seus motivos particulares - a classe trabalhadora como ameaça e impeditivo para a realização de seus projetos individuais. Assim, com um inimigo em comum, civis e militares uniram-se na perseguição e repressão aos trabalhadores e sindicalistas. Dessa união surgiu, segundo o relatório, um novo processo fabril contando com o Estado como agente patronal que submetia os trabalhadores a um constante monitoramento no interior das fábricas e se desdobrava em torturas, violações dos direitos trabalhistas, militarização das fábricas, criação e divulgação de listas com trabalhadores sindicalizados e processos de contratação baseados em critérios ideológicos. O relatório descreve ainda como a articulação entre as elites civil e militar resultou em uma legislação que permitiu uma exploração exacerbada do trabalho.

Mais especificamente considerando os trabalhadores do campo, o terceiro texto, nomeado Violações de direitos humanos dos camponeses, expõe, sob a ótica desses trabalhadores, o período do regime militar e suas consequências. Como era de se supor, a questão camponesa inicia com a discussão a respeito da concentração de terras e de como a reivindicação dessas terras por parte dos pequenos agricultores foi violentamente reprimida pelos grandes produtores rurais com o consentimento do Estado. O relatório destaca que tal prática não foi exclusiva do período ditatorial, contudo, durante o regime, o Estado foi participativo e conivente com a ação repressiva dos fazendeiros. Outra contribuição importante desse texto é a descrição do combate às Ligas Camponesas pelo governo totalitário no Nordeste brasileiro e do combate ao sindicalismo rural no Maranhão, além do relato sobre a dissolução do assentamento camponês localizado em Trombas e Formoso. Houve também repressão no Pará, onde os camponeses foram mortos, presos, torturados ou foram dados como desaparecidos devido a uma suposta cumplicidade com os guerrilheiros do Araguaia. O número de camponeses acusados ultrapassa uma centena e, destes, foram identificados 27 mortos.

O terceiro texto explica que a repressão aos trabalhadores rurais se espalhou pelo País e atingiu as cinco regiões brasileiras, passando por Pernambuco, Amazonas, Mato Grosso, Goiás, São Paulo, Rio 
de Janeiro e Rio Grande do Sul. Por meio da leitura desse texto, é possível compreender que a associação das elites rurais com as forças do Estado ganhou contornos oficiais durante o regime militar e que seu principal objetivo era reprimir violentamente os movimentos camponeses (que reivindicavam melhorias nas condições de trabalho, reforma agrária e direitos dos trabalhadores do campo), com o intuito de favorecer os interesses dos grandes fazendeiros.

O volume dois prossegue descrevendo, por meio de seu quarto texto, a participação das igrejas cristãs no processo da ditadura militar. Reconhecendo a pluralidade religiosa do Brasil, o relatório da $\mathrm{CNV}$ concentrou-se apenas nessa vertente religiosa em virtude (a) da limitação estrutural de realizar um levantamento que abrangesse a participação de todas as religiões atuantes no Brasil da época; e (b) do papel relevante ocupado pelas igrejas cristãs como ator histórico, social e político no contexto brasileiro. Nesse sentido, o texto procura problematizar a participação da Igreja Católica Apostólica Romana e das igrejas protestantes, tanto da perspectiva destas como instituições de apoio ao golpe quanto como em casos de perseguição, censura, prisões, torturas e morte sofridas por seus membros.

De forma similar aos camponeses, os indígenas, tratados no texto cinco, também sofreram durante o regime militar uma intensificação da violência contra eles. Assim como trabalhadores, estudantes e homossexuais, os índios foram categorizados pelo regime militar como inimigos do Estado e, por isso, como um risco à segurança nacional. Tal justificativa, segundo o relatório, é tão vã que não possui uma unidade, variando desde a suposta suscetibilidade dos índios à influência estrangeira até a existência de riquezas em seus territórios ou, ainda, por seus territórios estarem localizados na fronteira. Chega-se ao ponto de justificar tal perseguição pelo fato de as terras indígenas estarem no caminho de algum projeto desenvolvimentista. Assim, os índios brasileiros engrossavam a já extensa lista de inimigos do Estado, perseguidos e mortos pelo governo militar.

O sexto texto desse volume discute o posicionamento das universidades e o movimento estudantil. No período anterior ao golpe de 1964, as universidades contavam com um ambiente permeado por eventos políticos e uma ativa mobilização estudantil, consoante com os diversos diretórios acadêmicos e com a própria União Nacional dos Estudantes (UNE). Após o golpe militar, as representações estudantis foram fechadas e postas na ilegalidade, e as universidades (professores e alunos), assim como as fábricas, passaram a viver um constante monitoramento.

A questão do gênero também não é negligenciada pelo relatório da CNV. O texto sete contempla o caso de perseguição a lésbicas, gays, bissexuais, transexuais e transgêneros. Apesar de não haver um posicionamento declarado contra esse grupo (como havia contra os trabalhadores e comunistas), a ideologia que movia as intenções golpistas, segundo o relatório, "continha claramente uma perspectiva homofóbica, que relacionava a homossexualidade às esquerdas e à subversão" (CNV, 2014a, p. 291), representando uma ameaça à constituição da família tradicional, defendida pelas ideologias golpistas.

A relação entre as elites civis e militares, abordada no texto dois, é retomada com detalhes no texto oito, nomeado Civis que colaboraram com a ditadura, consubstanciados na figura do empresariado financiador e cúmplice do golpe. Esse texto explicita a participação, por exemplo, do empresariado na constituição do Instituto de Pesquisas e Estudos Sociais (IPES) e como, por meio desse órgão, pôde contribuir financeiramente com uma campanha midiática pré-golpe, que objetivava desestabilizar o governo democrático.

Citando nominalmente tanto os empresários quanto as empresas, o texto oito relata que o apoio dos empresários não se limitou ao suporte financeiro, mas estendeu-se também para outras ações mais operacionais, tais como o auxílio de infraestrutura, a cessão de carros e caminhões das frotas das empresas para tocaia e vigília aos que se posicionavam contra o governo e o fornecimento de alimentos às carceragens de presos políticos. O caso mais simbólico do apoio financeiro dos empresários e dos grupos empresariais foi o da Operação Bandeirantes (projeto-piloto que resultou na criação do Destacamento de Operações de Informação - Centro de Operações de Defesa Interna [DOI-CODI]) em todas as regiões do Brasil: 
Ao lado dos banqueiros, diversas multinacionais financiaram a formação da Oban, como os grupos Ultra, Ford, General Motors, Camargo Corrêa, Objetivo e Folha. Também colaboraram multinacionais como a Nestlé, General Eletric, Mercedes Benz, Siemens e Light. Um número incerto de empresários paulistas também contribuiu, já que a arrecadação de recursos contava com o apoio ativo da Federação das Indústrias do Estado de São Paulo (FIESP) [...] A Ford e a Volkswagen fornecia $[\mathrm{sic}]$ carros, a Ultragás emprestava caminhões e a Supergel abastecia a carceragem da rua Tutoia com refeições congeladas. Segundo Paulo Egydio Martins, que em 1974 assumiria o governo de São Paulo, "àquela época, levando-se em conta o clima, pode-se afirmar que todos os grandes grupos comerciais e industriais do estado contribuíram para o início da Oban" (CNV, 2014a, pp. 319-320).

Além disso, de acordo com o relatório, a participação dos empresários também ocorreu por meio da prática de delação de empregados considerados suspeitos. Dessa forma, o relatório apresenta uma vasta (mas não exaustiva) lista de empresas e empresários que participaram da conspiração, execução e manutenção do golpe militar, procurando implicar tais organizações em suas respectivas responsabilidades para com a sociedade brasileira. Assim, de acordo com o documento, as violações ocorreram principalmente em três frentes: (a) pelo uso da força repressiva e de controle por meio de perseguições, prisões, torturas; (b) pelo posicionamento do trabalhador como subversivo e inimigo da nação brasileira; e (c) pela criação e divulgação das listas negras.

Finalmente, o último texto do volume II se dedica a descrever os movimentos de resistência da sociedade civil em relação à ditadura, elencando os principais grupos e suas articulações, como o movimento estudantil; os movimentos culturais representados por canções, peças teatrais, artes plásticas e literatura; a imprensa alternativa e clandestina que visava informar sobre o que era censurado na grande mídia; as oposições político-partidárias; e os movimentos sociais e políticos, que incluíam organizações de moradores, movimentos feministas, movimentos negros e movimentos sindicais. Além desses movimentos, o texto destaca as grandes manifestações públicas que ocorriam durante o regime e a campanha pela anistia.

O terceiro volume do relatório final, por fim, contém a história de vida de cada um dos 434 mortos e desaparecidos políticos desde 1950 até 1985, conforme a Tabela 3.

Tabela 3

\section{Detalhamento do Volume 3 do Relatório Final da CNV}

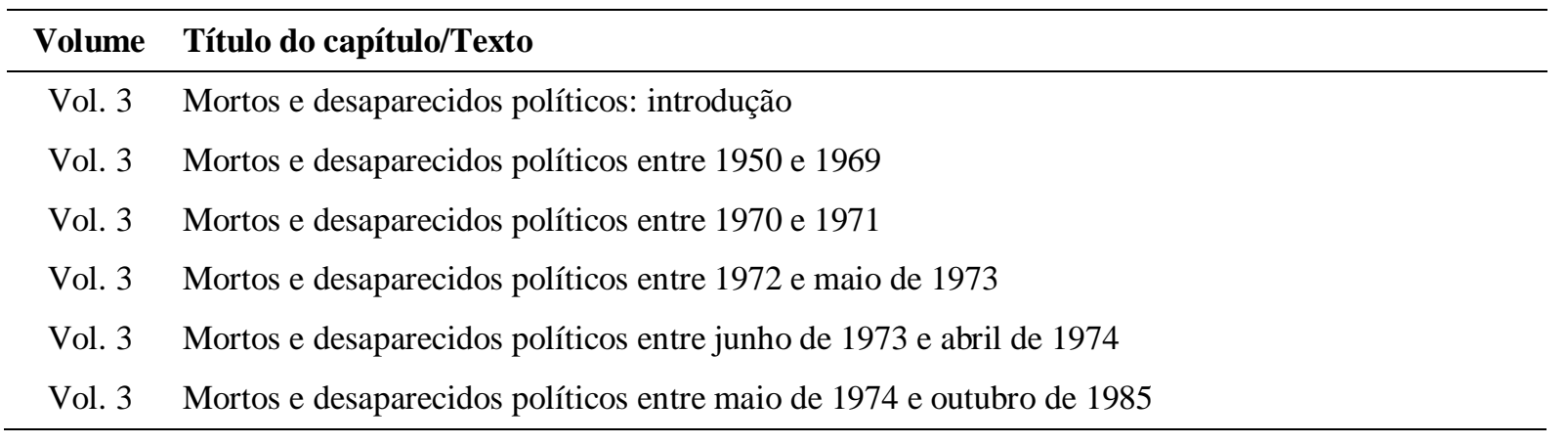

Nota. Fonte: Elaborada pelos autores com base no relatório final da Comissão Nacional da Verdade. (2014c). Relatório da Comissão Nacional da Verdade. Mortos e desaparecidos políticos (Vol. 3). Brasília, DF. Recuperado de http://www.cnv.gov.br/images/pdf/relatorio/volume_3_digital.pdf

Os relatos trazem fotos das vítimas, dados pessoais, biografia e, em algumas situações mais específicas, acerca de como o caso foi tratado até a instauração da CNV. Esse volume traz também, para cada um dos mortos e desaparecidos, as circunstâncias de seu desaparecimento e de sua morte, com as descrições das torturas sofridas e possíveis razões que possam ter levado à sua perseguição. A ideia é retratar de forma categórica o local de desaparecimento e morte, bem como a autoria do crime e toda a cadeia de comando envolvida. Baseado nisso, o relatório relaciona os envolvidos nas graves violações 
dos direitos humanos, listando as fontes de investigação, testemunhas e documentos. Cada descrição é finalizada com suas conclusões e recomendações sobre o caso.

\section{Contribuições para a Área de Estudos Organizacionais}

Como proposto no início deste trabalho, do ponto de vista de uma perspectiva histórica, os documentos gerados, sistematizados e disponibilizados pela CNV podem compor um valioso conjunto de fontes de informação para a área de estudos organizacionais, em particular, e para a área de Administração, em geral.

Esse conjunto adquire ainda maior relevância tendo em vista que as pesquisas e fontes documentais que identificam e/ou problematizam as ações e crimes de violação de direitos humanos empreendidas por empresários, empresas e grandes corporações são ainda escassas (ver, por exemplo: Campos, 2014; Dreifuss, 1981; Melo, 2012). Apesar disso, entretanto, cumpre destacar que alguns pesquisadores organizacionais estão atentos a essa situação e buscam reverter esse quadro, como é o caso dos recentes estudos sobre fraudes (A. P. P. Costa \& Wood, 2012) e crimes corporativos (Oliveira, 2015; Oliveira, Valadão, \& Miranda, 2013; Silveira \& Medeiros, 2014).

Assim, mesmo assumindo que os documentos produzidos e/ou entregues por requisição à comissão (e depois direcionados para o Arquivo Público Nacional) sofreram nesse processo alguma forma de expurgo, censura ou crítica, considera-se esse corpus bastante relevante como contribuição para a área de estudos organizacionais. Por conseguinte, reconhecendo que as possibilidades são inúmeras, elencamos quatro perspectivas e/ou avenidas de pesquisas como reflexões iniciais.

A primeira avenida de pesquisa diz respeito às fontes documentais acerca do apoio e da participação da sociedade civil na constituição e manutenção do governo militar brasileiro. Além dos depoimentos, o relatório final da comissão é bastante claro no que diz respeito à participação das empresas no êxito do golpe militar de 1964. O documento afirma que "o papel do grande setor privado nacional e estrangeiro foi decisivo, por meio da mobilização das associações de classe há muito existentes e das novas entidades da sociedade civil, criadas naquele contexto" (CNV, 2014a, p. 306). Essa participação assumiu diversas formas, desde o apoio ideológico e político ao movimento, passando por suporte financeiro e de materiais, até chegar ao apoio às estruturas de repressão e tortura do governo ditatorial brasileiro. Cabe ressaltar que, conforme os documentos acerca desse tema iam surgindo nos resultados dos trabalhos da comissão, a repercussão na imprensa brasileira era imediata. Várias reportagens foram publicadas com títulos, como: Empresas que apoiaram a ditadura poderão ser processadas (Jimenez, 2013); Ao menos 70 empresas colaboraram com a ditadura (Gombatta, 2014); e Mais de 80 empresas colaboraram com a ditadura militar no Brasil: a Comissão Nacional da Verdade divulga uma lista de empresas que delataram funcionários (Borges, 2014).

Assim, por exemplo, mediante o acesso aos documentos disponíveis (inclusive o relatório final), é possível compreender que o golpe militar de 1964 e a posterior manutenção, tanto da ditadura civilmilitar brasileira quanto de seu aparato de repressão, tiveram o apoio (muitas vezes financeiro) de empresários, de empresas (nacionais e estrangeiras), de suas associações e federações (como foi o caso da FIESP e da FIRJAN) e de organizações da sociedade civil, como institutos e centros de estudos e pesquisas (como foi o caso do IPES e do IBAD). É nesse sentido que o estudo da atuação desses agentes sociais, do impacto e da dimensão de suas ações, de sua influência tanto nas políticas governamentais quanto nas políticas e práticas de repressão e violação dos direitos humanos pode oferecer uma nova e fértil área de pesquisa. $\mathrm{O}$ aprofundamento dessas questões, sob a fundamentação de novos documentos, abre, por outro lado, novas possibilidades de discussão sobre o papel das empresas na sociedade e sobre as ideias usualmente atreladas a esse papel, tais como: bem-estar da coletividade, responsabilidade social, sustentabilidade e até mesmo responsabilidade histórica. Ao mesmo tempo, os documentos permitem aos pesquisadores discutir a responsabilidade dessas organizações à luz das convenções internacionais acerca dos direitos humanos. Sobre isso, as graves violações dos direitos humanos 
detalhadas e expostas no primeiro volume do relatório final podem servir de fonte quando bem articuladas com os textos do volume dois sobre a participação do empresariado.

Nessa mesma linha de pensamento, podem também ser desenvolvidas pesquisas que discutam as dimensões políticas, sociais e ideológicas das relações entre empresas, empresários e governo, buscando identificar de que forma estes se beneficiaram do apoio dado ao golpe militar e como esse apoio se reflete nos dias de hoje. De forma complementar, é importante investigar empresários, empresas e demais organizações (sindicatos, partidos políticos, organizações religiosas e universidades) que se posicionaram contra o regime militar ou se recusaram a apoiá-lo e foram perseguidos por meio de cassações, investigações e prisões arbitrárias (Motta, 2014; Sasaki, 2005).

Uma segunda relevante avenida de pesquisa contemplaria estudos sobre as diversas redes organizacionais da sociedade civil envolvidas no dia a dia dos trabalhos da CNV. Estas tinham o objetivo de atuar na formação de demandas de diferentes setores da sociedade civil e na fiscalização dos compromissos estabelecidos, como foi o caso do Instituto Superior de Estudos Religiosos (ISER), do Coletivo RJ Memória, Verdade e Justiça, da OAB/RJ, do Grupo Tortura Nunca Mais, entre outros. Ou seja, pode ser bastante profícuo o interesse de pesquisadores organizacionais por buscar entender e problematizar as diferentes vozes que, em rede, interagem, negociam e disputam espaço, ou para influenciar ou para dar suporte aos trabalhos da comissão.

Cabe salientar que, ao assim proceder, essas vozes estão construindo, conjuntamente, a releitura da história da ditadura civil-militar brasileira. Ao mesmo tempo, as fontes históricas da CNV também podem contribuir para um melhor entendimento acerca da atuação conjunta (cooperativa ou não) das diversas comissões da verdade instituídas tanto no âmbito dos poderes Executivo e Legislativo (como foi o caso das comissões da verdade estaduais) quanto no âmbito das instituições públicas e privadas (universidades e entidades de classe).

Uma terceira avenida de pesquisa sugerida tem como foco as relações de trabalho cujos pesquisadores podem se beneficiar das informações contidas nos documentos disponibilizados pela $\mathrm{CNV}$ para desenvolver estudos que abordem e problematizem: as relações de trabalho entre empregados e empregadores durante o período; as práticas de políticas de gestão de recursos humanos sob um contexto de governo autoritário; a questão dos sindicatos, das arbitrariedades trabalhistas e do não exercício dos direitos trabalhistas; além dos desdobramentos gerados pelas políticas governamentais para com os trabalhadores.

De forma mais específica, pode-se problematizar, por exemplo, os procedimentos e as medidas de reparação (como o direito à reintegração ao trabalho ou a contagem de tempo dos exilados políticos para fins de aposentadoria) e os possíveis desdobramentos para toda uma geração de trabalhadores cuja carreira foi construída sob a coação e a vigilância de um regime militar autoritário, repressivo e desarticulador. Ademais, pesquisas relacionadas aos processos de flexibilização e de precarização das relações de trabalho podem utilizar os documentos da CNV na tentativa de melhor compreender como as práticas de gestão e as legislações trabalhistas adotadas durante o regime militar se refletem na condição atual do trabalhador urbano e rural.

Desse modo, abrem-se ainda possibilidades de estudos sobre a ideologia que fundamentou o golpe, sua disseminação, a participação das empresas nesse processo e as tentativas de manutenção da estrutura social hegemônica. Há também, para esses pesquisadores, a oportunidade de estudos sobre as relações de poder dentro das organizações sob a influência de um Estado centralizador e repressivo, além das formas de lutas e resistências ocorridas no período da ditadura no interior das organizações e da sociedade. Por último, em relação aos sindicatos, pode-se buscar melhor compreender, entre outras questões, a importante dinâmica construída no período em um contexto (a) de pouco espaço para ação e representação dos interesses dos trabalhadores; (b) de desorganização operária; e (c) de reorientação conservadora dos sindicados e a formação, a partir dos anos 1970, do chamado novo sindicalismo (Antunes \& Santana, 2014). 
A última avenida proposta permite aos pesquisadores refletirem sobre o tema da história e da memória das empresas. Assumindo que tanto a memória quanto o esquecimento acerca dos fatos históricos podem ser instrumentos de dominação, de legitimação e de construção de identidade organizacional (Decker, 2013; Rowlinson, Booth, Clark, Delahaye, \& Procter, 2010), pode-se perguntar como as empresas se apropriam de seu passado e contam hoje a sua história e a sua atuação na sociedade durante o período da ditadura civil-militar brasileira. Expurgam o que não é considerado por seus clientes e acionistas como ético? Assumem o apoio e a ajuda financeira aos aparelhos de repressão? No entanto, como proceder quando, no processo de constituição de um passado organizacional pretendido, versões oficiais e hegemônicas são questionadas quando contextualizadas e comparadas com novas fontes documentais? Em outras palavras, como as empresas constroem o seu passado pretendido quando confrontadas com documentos e fontes históricas que as contradizem? Ou, sob outra perspectiva, como as empresas e empresários lidam com fatos e eventos do passado que talvez não sejam tão agregadores em termos de benefícios de imagem e de reputação organizacional nos dias de hoje?

Enfim, como contar ou explicar a história da empresa - de forma despolitizada e neutra - quando a própria história política e social do país apresenta indícios de vínculos estabelecidos entre empresas, governos e aparatos de repressão? Oportunidade de negócios? Luta ideológica? Manutenção da ordem? Apreensão acerca dos desdobramentos de uma luta armada? Em processos de transição de governos autoritários para governos democráticos, a sociedade e seus agentes sociais tendem a viver o dilema entre memória demais ou esquecimento demais. É nesse sentido que A. M. Costa e Saraiva (2011, p. 1762) argumentam que, "discutir a apropriação da memória pelas empresas como pauta dos estudos organizacionais significa, entre outras coisas, resgatar a perspectiva histórica e problematizar a opção dos gestores das organizações a respeito do que lembrar - e do que esquecer".

Por fim, um último ponto diz respeito à própria construção de novas versões de fatos históricos. Uma narrativa oficial não é sinônimo de uma narrativa verdadeira e aproxima-se mais da ideia de uma narrativa consagrada e/ou legitimada por uma sociedade posicionada no tempo e no espaço. Esse talvez seja o ensinamento mais importante do trabalho com fontes históricas: o entendimento de que não existe uma visão unívoca a respeito do passado. Pelo contrário, o que as fontes e o acervo documental da CNV nos mostram é exatamente o recorrente surgimento de novas versões sobre o passado, sempre à luz de novas inquietações do presente.

Por isso é tão importante o papel do pesquisador nesse processo. Pode-se afirmar que nunca se produziram tantos documentos como na contemporaneidade e, ao mesmo tempo, também nunca se consideraram tantos documentos como fontes históricas passíveis de serem consultadas e discutidas. Mas em que medida as fontes e acervos históricos ajudam os pesquisadores organizacionais a pensar e problematizar seus objetos de pesquisa? Segundo François (1998, p. 158) "as fontes só começam a falar a partir do momento em que as interrogamos, e a qualidade das respostas que elas podem dar coincide com a qualidade das questões que se formulam”. Nesse sentido, quais interrogações poderiam ser feitas? Como usar documentos históricos disponíveis para desnaturalizar e problematizar versões oficiais e hegemônicas acerca dos fenômenos organizacionais? Ou seja, a Comissão Nacional da Verdade pode trazer à tona novos atores cuja participação no processo ditatorial era desconhecida, minimizada ou até mesmo camuflada pela história oficial e consagrada do período, como é o caso, no nosso entendimento, das empresas e da elite empresarial brasileira.

\section{Referências}

Abrão, P. (2011). A lei de anistia no Brasil: as alternativas para a verdade e a justiça. Acervo, 24(1), 119-138.

Adam, A. P., Silva, D. B., \& Leonetti, P. (2013). Direitos humanos no Brasil: limites e possibilidades para a eficácia das sentenças prolatadas pela CIDH. Revista Direitos Humanos e Democracia, $1(2), 4-60$. 
Alcadipani, R., \& Bertero, O. C. (2012). Guerra Fria e ensino do management no Brasil: o caso da FGVEAESP. Revista de Administração de Empresas, 52(3), 284-299.

Anteby, M., \& Molnar, V. (2012). Collective memory meets organizational identity: remembering to forget in a firm's rhetorical history. Academy of Management Journal, 55(3), 515-540. http://dx.doi.org/10.5465/amj.2010.0245

Antunes, R., \& Santana, M. A. (2014). Para onde foi o "novo sindicalismo"? Caminhos e descaminhos de uma prática sindical. In D. A. Reis, M. Ridenti, \& R. P. Motta (Eds.), A ditadura que mиdou o Brasil (pp. 128-141). Rio de Janeiro: Zahar.

Arruda, R. (2013, agosto, 26). Crise na Comissão da Verdade ameaça relatórios sobre repressão. $O$ Estadão, Recuperado em 01, dezembro, 2014, de http://politica.estadao.com.br/noticias/eleicoes,crise-na-comissao-da-verdade-ameaca-relatoriosobre-repressao-imp-, 1067921

Bloch, M. (2001). Apologia da história ou o ofício do historiador. Rio de Janeiro, RJ: Jorge Zahar.

Bocchini, L., \& Bonis, G. (2013, junho 18). Claudio Fonteles deixa a Comissão Nacional da Verdade. Revista Carta Capital. Recuperado em 01, dezembro, 2014, de http://www.cartacapital.com.br/politica/claudio-fonteles-deixa-a-comissao-nacional-da-verdade4311.html

Borges, B. (2014, setembro 8). Mais de 80 empresas colaboraram com a ditadura militar no Brasil: a Comissão Nacional da Verdade divulga uma lista de empresas que delataram funcionários. El País. Recuperado em 01, dezembro, 2014, de http://brasil.elpais.com/brasil/2014/09/08/politica/1410204895_124898.html

Campos, P. H. P. (2014). Estranhas catedrais: as empreiteiras brasileiras e a ditadura civil-militar, 1964-1988. Niterói, RJ: Editora da UFF.

Comissão Nacional da Verdade. (2012, setembro 12). Comissão da Verdade pede ao MEC apoio para pesquisa científica sobre a ditadura brasileira. Recuperado em 01, dezembro, 2014, de http://www.cnv.gov.br/outros-destaques/94-comissao-da-verdade-pede-ao-mec-apoio-parapesquisa-cientifica-sobre-a-ditadura-brasileira.html

Comissão Nacional da Verdade. (2013, outubro 24). Audiências públicas e diligências. Recuperado em 01, dezembro, 2014, de http://www.cnv.gov.br/audi\%C3\%AAncias-p\%C3\%BAblicas.html

Comissão Nacional da Verdade. (2014b). Relatório da Comissão Nacional da Verdade (Vol. 1). Brasília, DF. Recuperado de http://www.cnv.gov.br/images/pdf/relatorio/volume_1_digital.pdf

Comissão Nacional da Verdade. (2014c). Relatório da Comissão Nacional da Verdade. Mortos e desaparecidos políticos (Vol. 3). Brasília, DF. Recuperado de http://www.cnv.gov.br/images/pdf/relatorio/volume_3_digital.pdf

Comissão Nacional da Verdade. (2014a). Relatório da Comissão Nacional da Verdade. Textos temáticos (Vol. 2). Brasília, DF. Recuperado de http://www.cnv.gov.br/images/pdf/relatorio/volume_1_digital.pdf

Comissão Nacional da Verdade. (2015a, janeiro 30). Grupos de trabalho. Recuperado em 01, dezembro, 2015, de http://www.cnv.gov.br/institucional-acesso-informacao/grupos-de-trabalho.html

Comissão Nacional da Verdade. (2015b, fevereiro 2). Laudos periciais. Recuperado em 24, março, 2015 de http://www.cnv.gov.br/laudos-periciais.html 
Corte Interamericana de Direitos Humanos. (2010, novembro 24). Caso Gomes Lund e outros ("Guerrilha do Araguaia") vs. Brasil. Recuperado de http://www.corteidh.or.cr/docs/casos/articulos/seriec_219_por.pdf

Costa, A. M., \& Saraiva, L. A. S. (2011). Memória e formalização social do passado nas organizações. Revista de Administração Pública, 45(6), 1761-1780. http://dx.doi.org/10.1590/S003476122011000600007

Costa, A. P. P. da, \& Wood, T. (2012, julho/agosto). Fraudes corporativas. Revista de Administração de Empresas, 52(4), 464-472. http://dx.doi.org/10.1590/S0034-75902012000400008

Decker, S. (2013). The silence of the archives: business history, post-colonialism and archival ethnography. Management \& Organizational History, 8(2), 155-173. http://dx.doi.org/10.1080/17449359.2012.761491

Decker, S. (2014). Solid intentions: an archival ethnography of corporate architecture and organizational remembering. Organization, 21(4), 514-542. http://dx.doi.org/10.1177/1350508414527252

Decreto $n^{\circ} 7.037$ de 21 de dezembro de 2009. (2009). Aprova o Programa Nacional de Direitos Humanos - PNDH-3 e dá outras providências. Diário Oficial da União, DF: Presidência da República.

Dias, R. B. (2013). A Comissão Nacional da Verdade: disputa da memória sobre o período da ditadura e o tempo presente. Patrimônio \& Memória, 9(1), 71-95.

Dreifuss, R. A. (1981). 1964: a conquista do Estado - ação política, poder e golpe de classe. Petrópolis, RJ: Vozes.

Duailibi, J. (2014, abril). A verdade da comissão. Revista Piauí, edição 91. Recuperado em 13, outubro, 2014, de http://piaui.folha.uol.com.br/materia/a-verdade-da-comissao/

Durepos, G., Mills, A. J., \& Mills, J. H. (2008). Tales in the manufacture of knowledge: writing a company history of Pan American World Airways. Management \& Organizational History, 3(1), 63-80. http://dx.doi.org/10.1177/1744935908090998

Foster, W. M., Suddaby, R., Minkus, A., \& Wiebe, E. (2011). History as social memory assets: the example of Tim Hortons. Management \& Organizational History, 6(1), 101-120. http://dx.doi.org/10.1177/1744935910387027

François, E. (1998). Os "tesouros" de Stasi ou a miragem dos arquivos. In J. Boutier \& D. Julia (Orgs.), Passados recompostos: campos e canteiros da história (pp. 155-161). Rio de Janeiro: Editora UFRJ.

Gombatta, M. (2014, setembro 8). Ao menos 70 empresas colaboraram com a ditadura. Revista Carta Capital. Política. Recuperado em 1, dezembro, 2014, de http://www.cartacapital.com.br/politica/ao-menos-70-empresas-colaboraram-com-a-ditadura5660.html

Grupo Tortura Nunca Mais/RJ. (2011, junho). Comissão da Verdade: mais uma farsa, mais um engodo. Jornal do Grupo Tortura Nunca Mais/RJ, ano 25(77). Recuperado de www.torturanuncamaisrj.org.br/jornal/gtnm_77/comissao_verdade.html

Instituto de Estudos da Religião. (2012). $1^{o}$ relatório semestral de acompanhamento da Comissão Nacional da Verdade. Recuperado em 01, dezembro, 2014, de http://pfdc.pgr.mpf.mp.br/temasde-atuacao/direito-a-memoria-e-a-verdade/comissao-nacional-da-verdade/i-relatorio-semestralde-acompanhamento-da-comissao-nacional-da-verdade

Jimenez, C. (2013, abril 19). Empresas que apoiaram a ditadura poderão ser processadas. Revista Isto é Dinheiro. Entrevista. Recuperado em 01, dezembro, 2014, de 
http://www.istoedinheiro.com.br/noticias/entrevistas/20130419/empresas-que-apoiaramditadura-poderao-ser-processadas/148095.shtml

Kipping, M., Wadhwani, R. D., \& Bucheli, M. (2014). Analyzing and interpreting historical sources: a basic methodology. In M. Bucheli \& D. R. Wadhwani (Eds.), Organizations in time: history, theory and methods (pp. 305-329). Oxford: Oxford University Press.

Lei $n^{\circ} 12.528$, de 18 de novembro de 2011. (2011). Cria a Comissão Nacional da Verdade no âmbito da Casa Civil da Presidência da República. Diário Oficial da União, DF: Presidência da República.

Lipartito, K. (2014). Historical sources and data. In M. Bucheli \& D. R. Wadhwani (Eds), Organizations in time: history, theory and methods (pp. 284-304). Oxford: Oxford University Press.

Melo, J. J. (2012). Boilesen, um empresário da ditadura: a questão do apoio do empresariado paulista à Oban/Operação Bandeirantes, 1969-1971 (Dissertação de mestrado). Universidade Federal Fluminense, Niterói.

Motta, R. P. S. (2014). As universidades e o regime militar. Rio de Janeiro, RJ: Zahar.

Oliveira, C. R. (2015). Crimes corporativos e estudos organizacionais: uma aproximação possível e necessária. Revista de Administração de Empresas, 55(2), 202-208. http://dx.doi.org/10.1590/S0034-759020150209

Oliveira, C. R., Valadão, V. M., Jr., \& Miranda, R. (2013). Culpada ou inocente? Comentários de internautas sobre crimes corporativos. Revista de Administração de Empresas, 53(6), 617-628. http://dx.doi.org/10.1590/S0034-759020130609

Paiva, V., \& Pomar, P. E. da R. (2011, outubro). Se a ditadura acabou, onde está a democracia? Comissão da verdade sem autonomia atesta pacto entre governo e militares. Revista Adusp, (51), 112-117. Recuperado de http://www.adusp.org.br/files/revistas/51/r51a16.pdf

Pinto, S. R. (2010). Direito à memória e à verdade: Comissões de Verdade na América Latina. Revista Debates, 4(1), 128-143.

Rowlinson, M., Booth, C., Clark, P., Delahaye, A., \& Procter, S. (2010). Social remembering and $\begin{array}{lllll}\text { organizational memory. } & \text { Organization }\end{array}$ http://dx.doi.org/10.1177/0170840609347056

Rowlinson, M., Hassard, J., \& Decker, S. (2014). Research strategies for organizational history: a dialogue between historical theory and organizational theory. Academy of Management Review, 39(3), 250-274. http://dx.doi.org/10.5465/amr.2012.0203

Santos, C. M. (2010). Memória na Justiça: a mobilização dos direitos humanos e a construção da memória da ditadura no Brasil. Revista Crítica de Ciências Sociais, (88), 127-154.

Sasaki, D. L. (2005). Pouso forçado: a história por trás da destruição da Panair do Brasil pelo Regime Militar. Rio de Janeiro: Record.

Schmidt, B. B. (2007). Cicatriz aberta ou página virada? Lembrar e esquecer o golpe de 1964 quarenta anos depois. Revista Anos 90, 14(26), 127-156.

Secretaria de Direitos Humanos. (2008). Democracia, desenvolvimento e direitos humanos: superando as desigualdades. Resoluções aprovadas na $11^{a}$ Conferência Nacional de Direitos Humanos, Recuperado em $\quad 01, \quad$ dezembro, 2014, de http://www.ipea.gov.br/participacao/images/pdfs/conferencias/Direitos_humanos_XI/deliberaco es_11_conferencia_direitos_humanos.pdf 
Silveira, R. A. da, \& Medeiros, C. R. O. (2014, abril/junho). Viver e morrer pelo trabalho: uma análise da banalidade do mal nos crimes corporativos. Revista O\&S, 21(69), 217-234. http://dx.doi.org/10.1590/S1984-92302014000200002

Usdiken, B., \& Kipping, M. (2014). History and organization studies: a long-term view. In M. Bucheli \& D. R. Wadhwani (Eds.), Organizations in time: history, theory and methods (pp. 33-55). Oxford: Oxford University Press.

Yates, J. (2014). Understanding historical methods in organization studies. In M. Bucheli \& D. R. Wadhwani (Eds.), Organizations in time: history, theory and methods (pp. 265-283). Oxford: Oxford University Press.

YouTube. (2014, dezembro 10). Comissão Nacional da Verdade. Entrega do relatório final da CNV. $\begin{array}{lllll}\text { Brasília, } & \text { DF. } & \text { Recuperado } & 2014\end{array}$ https://www.youtube.com/user/comissaodaverdade/

\section{Dados dos Autores}

Alessandra Sá Mello Costa

Rua Marquês de São Vicente, 225, Gávea, 22451-900, Rio de Janeiro, RJ, Brasil. E-mail: alessandra.costa@iag.puc-rio.br

Marcelo Almeida de Carvalho Silva

Rua Marquês de São Vicente, 225, Gávea, 22451-900, Rio de Janeiro, RJ, Brasil. E-mail: marceloacs@ @otmail.com 